\title{
GOOGLEMAPS AND BUS TRACKING
}

\begin{tabular}{|l|l|l|l|}
\hline Shwetha NR & Mayur J & $\begin{array}{l}\text { Dr. Chetana Hegde, } \\
\text { Associate Professor }\end{array}$ & $\begin{array}{l}\text { Prof. Rajani Narayan } \\
\text { Associate Professor }\end{array}$ \\
$\begin{array}{l}\text { RNS Institute of } \\
\text { Technology }\end{array}$ & Department of MCA & RNS Institute of Technology \\
$\begin{array}{l}\text { Bangalore, India } \\
\text { shwetha.rigel@gmail.com }\end{array}$ & $\begin{array}{l}\text { Bangalore, India } \\
\text { mayur.genius16@gmail.com }\end{array}$ & $\begin{array}{l}\text { Bangalore } \\
\text { chetana.mca@gmail.com }\end{array}$ & $\begin{array}{l}\text { Bangalore } \\
\text { rajanibhuvan@gmail.com }\end{array}$ \\
\hline
\end{tabular}

Abstract - GPS technology is one of the technologies that are used in day to day transportation life. We can use the GPS to track the public transportation vehicle which saves passengers time.

This system can be used to solve the issue of waiting time of the passengers for bus. This system uses the Google Maps service that makes use of the GPS system. By using this system passengers can get to know where exactly the bus is and passengers can get to know the approximate time required for bus to reach the desired point and the scheduled route of how the bus will travel. In a way the passenger using this system can track the buses in any location.

\section{Keywords—GPS; Google Maps; Track; Trip}

\section{INTRODUCTION}

The world has become small and people have started navigating to different locations across the world.

The world is moving so fast that the time has become one of the most important aspects of every individual. It wouldn't be wrong if we say Time is valued as money. In such a situation when we are new to a place it is difficult for us to find the routes, transportation facilities etc of that place.

The most common mode of transport would be the bus transport in most of the places. In new places we will not know the different buses that are available from one source to certain destination so we might either end up waiting for a long time waiting for the bus or might board the wrong bus.

This is the kind of situation where our concept/system comes into picture. The system will be used to locate the buses that travel from a particular source to destination. With Google Maps help we can get to know the bus numbers that travel along the particular route from a source to a destination. Using these bus numbers we can track the current location of the bus. Also we can get to know what time it might take to reach our source. Thus helping us to utilize our time efficiently and making our travel more comfortable and reliable.

The system is very user friendly and simple. It can be used as web application or in the form of a mobile app. In both the cases the user must have the internet facility and in case of mobile app the user should have installed the mobile app.

When the user enters the bus number and the stop name the user can get to know the time that the bus takes to reach the stop.
To locate the bus on the map the user must enter the bus number. The system would show the current location of the bus along with its trip route.

\section{LITERATURE SURVEY}

Real-time tracking using GPS has been applied in various applications such as fleet management system, Cab Systems etc. But implementing the GPS tracking on the public buses is the new concept that we are trying to bring about.

The main components of this system include the database that stores the geographically referenced data and the other is the Google Maps on which the geographically referenced data are presented. Among the important components of this system is the Google Maps. Through maps the passengers will be able to track the buses.

\section{SOFTWARE PROGRAM}

The software programming is done in java. The co-ordinates i.e the latitude and longitude will be received by the GPS and is stored into the database.

Figure 3.1 shows the flowchart of the system using GPS:

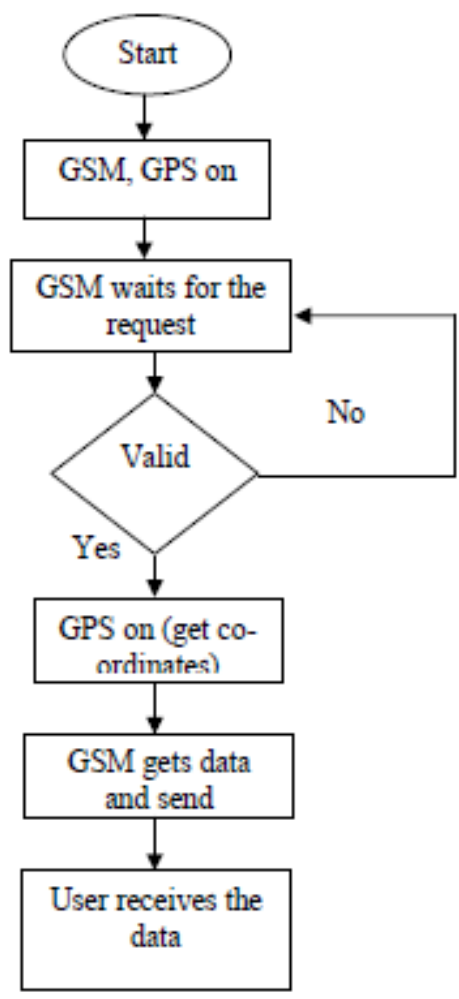

Figure 3.1 Program flow chart of the tracking system. 


\section{ELK Asia Pacific Journals - Special Issue ISBN: 978-81-930411-5-4}

Asia Pacific Journals

\section{HARDWARE}

GPS - GPS stands for Global Positioning System. They are majorly used for tracking and navigation purpose. In our system the GPS gives information about the current position of the buses.

GSM - GSM stands for Global System for Mobile Communications. The GSM modem is used for transmitting and receiving the data.

SIM 300 is a tri- band GSM/GPRS engine.

SmartPhone - We need a smart phone to download and install the app. Also for the purpose of internet connection through which the app can work.

Display - The web application would run on monitor display with internet connection on

\section{APPLICATION}

The project implementation will include the following components:

The user interface - The user interface consists of the map view to track the buses and to track the defined route of the bus.

User database - The details of the user and the latitude and longitude of the buses are stored in the database. The latitude and longitude of all the buses are stored as the Google Map APIs are based on the latitude and longitude.

Java file - The file was put on the server meant for the experiment. The working functionality and database connections are stored into this file. The Google API's working and functions are mentioned in this file.

The Google maps will make use of the markers that is used for the purpose of locating the position of the buses. These markers will locate the current latitude and longitude of all the buses. Each bus will have a separate marker. 5.1

Each bus with a marker would be seen as shown in Figure

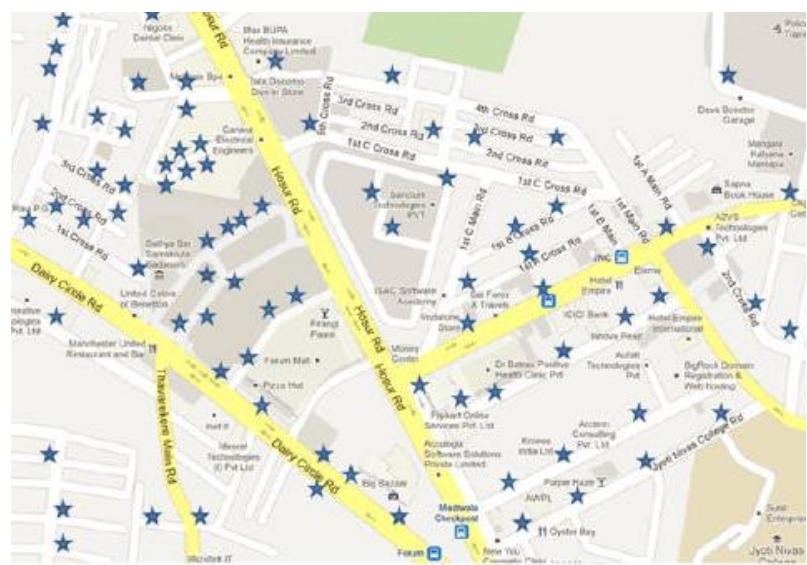

Figure 5.1 Bus represented as markers on map
The passenger or the user can make use of the Google Maps if they are not aware of the bus stop location or the buses along that route.

Figure 5.2 Shows the bus stop name and bus numbers that are displayed with the help of Google Maps.

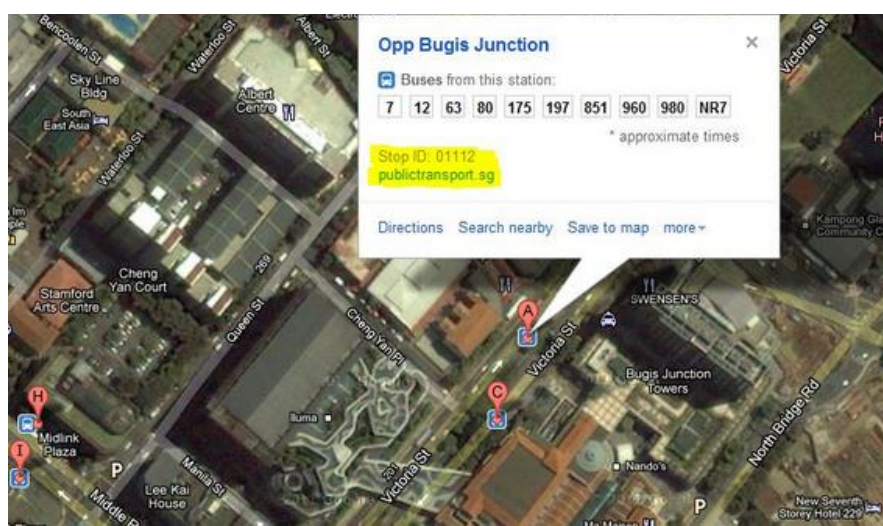

Figure 5.2 Name and location of the bus-stop with the details of the bus numbers.

\section{CONCLUSION}

The purpose of our system/project is to ease the mode of transportation through bus.

The system also takes care of making the travel of every passenger comfortable without any wastage of time.

\section{ACKNOWLEDGEMENT}

We would like to thank to our supervisors for encouraging us to submit our paper and also to our college for hosting this and providing us as opportunity to showcase our ideas.

\section{REFERENCES}

[3] Nagaraja, B. G.; Rayappa, R.; Mahesh, M.; Patil, C.M.; Manjunath, T. C., "Design \& Development of a GSM Based Vehicle Theft

[4]. Fleischer, P.B;"Design and development of GPS/GSM"

based vehicle tracking and alert system for commercial inter-city buses," Adaptive Science \& Technology (ICAST), 2012 IEEE 4th International Conference. 